University of Nebraska - Lincoln

DigitalCommons@University of Nebraska - Lincoln

3-2-2018

\title{
A Drone by Any Other Name: Purposes, End-User Trustworthiness, and Framing, but not Terminology, Affect Public Support for Drones
}

Lisa M. PytlikZillig

Brittany Duncan

Sebastian Elbaum

Carrick Detweiler

Follow this and additional works at: https://digitalcommons.unl.edu/lpz

Part of the Administrative Law Commons, Counseling Commons, Dispute Resolution and Arbitration Commons, Family Law Commons, Juvenile Law Commons, Law and Psychology Commons, Law and Society Commons, Psychology Commons, and the Public Law and Legal Theory Commons

This Article is brought to you for free and open access by the Public Policy Center, University of Nebraska at DigitalCommons@University of Nebraska - Lincoln. It has been accepted for inclusion in Lisa PytlikZillig Publications by an authorized administrator of DigitalCommons@University of Nebraska - Lincoln. 


\title{
A Drone by Any Other Name:
}

\author{
Purposes, End-User Trustworthiness, and \\ Framing, but not Terminology, \\ Affect Public Support for Drones
}

\author{
Lisa M. PytlikZillig, Brittany Duncan, \\ Sebastian Elbaum, and Carrick Detweiler
}

Projections indicate that, as an industry, unmanned aerial vehicles ooo jobs and $\$ 80$ billion in economic growth to the U.S. by 2025 [1]. However, these promising projections do not account for how various publics may perceive such technologies. Understanding public perceptions is important because the attitudes of different groups can have large effects on the trajectory of a technology, strongly facilitating or hindering technology acceptance and uptake [2].

To advance understanding of U.S. public perceptions of UAV technologies, we conducted a nationwide survey of a convenience sample of 877 Americans recruited from Amazon's pool of Mechanical Turk (MTurk) workers. In our surveys, we used short scenarios to experimentally vary UAV characteristics, the end-users of the technology, and certain communication factors (terminology and framing). This allowed us to investigate the impacts of these factors alone and in combination.

Published in IEEE Technology and Society Magazine, 2 March 2018, pp 80-91.

DOI 10.1109/MTS.2018.2795121

Copyright 2018 IEEE; used by permission. 
In addition, given the conflicts that sometimes arise around scientific findings and technologies (e.g., climate change, vaccines, [3], [4]), we also gave explicit attention to whether and how public support for UAVs varied by self-reported political ideology, issue attitudes, and perceptions of end-user trustworthiness. Finally, because UAVs for civilian purposes represented relatively new technologies at the time of the first survey, we examined whether public opinion is changing over time, as more people become aware of UAVs. We thus administered the same survey twice, separated by one year, in the fall of 2014 and 2015.

The results of our experimental manipulations revealed a surprising lack of impact of terminology and UAV autonomy, a small impact of message framing and UAV end-user, and a relatively large impact of UAV purpose. We did not find that public attitudes changed much over the year between samples, and perceptions of end-user trustworthiness were strong predictors of public support. Still, our regression models only accounted for about $40 \%$ of the variance in public support, suggesting that additional variables should be studied in future work to gain a more complete understanding of public support for UAVs. We also found evidence of a small amount of political polarization of public opinion related to who was using the UAVs for what purpose, and this polarization appeared to be changing over time.

Taken together, our results - which may be especially useful to UAV designers, marketers, and policy makers - suggest there is a need to establish that the UAVs are used for valued purposes and by users that publics find to be trustworthy. However, public judgments might be significantly impacted by personal or local ideologies rather than national priorities. In the next section, we describe in more detail prior research on public support for UAVs, and how we formulated our research questions and hypotheses. We then describe our methods, results, and findings in greater detail.

\section{Background and Research Questions}

In this research, our primary interest was to advance understanding of factors that impact public support - potentially including politically polarized support - for UAVs in the U.S. Some of our research

questions were derived from questions facing professionals designing 


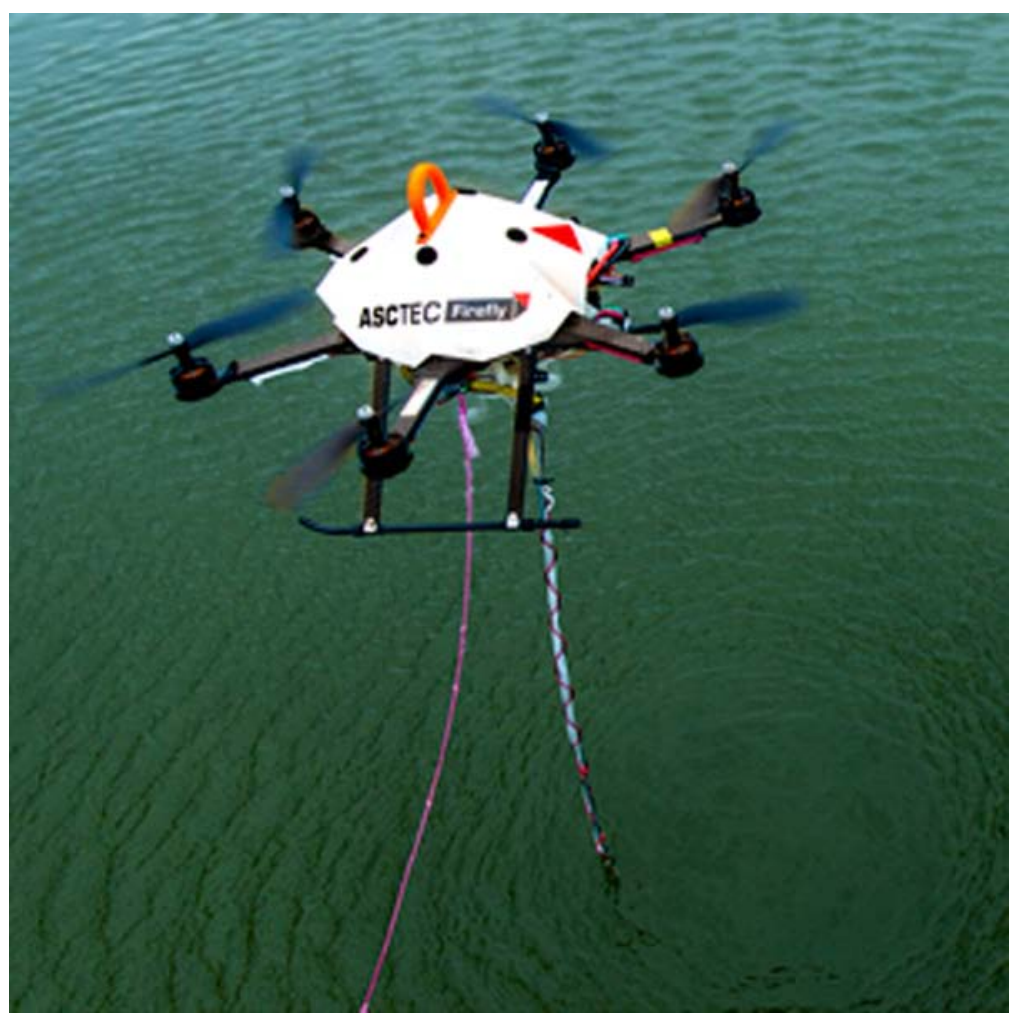

Figure 1. Photograph of the water sampling UAV in the field (not shown to participants).

UAVs, such as, does it matter what the technologies are called? Other questions were inspired by prior social science findings, for instance, how easy is it to evoke political polarization in response to UAVs?

\section{Communicating about UAVs: Terminology and Framing}

Some UAV industry professionals, concerned about how terminology might impact public perceptions, have tried to persuade the U.S. media to stop calling the technology "drones." Their concern is that the word "drone" evokes negative visions - perhaps of large predatory war instruments unthinkingly and unapologetically completing their missions without regard for collateral damage [5].

Social science theory and research also suggests that the terminology used to describe objects can influence people's perceptions. Euphemistic labeling refers to how different terms (e.g., military force vs. war; collateral damage vs. innocent victims) impact people's responses 
to verbal descriptions of events and objects [6], [7]. In general, language does matter, and different terms and phrases often are associated with different emotions and cognitive associations [8]. Although a prior study found terminology had little or no effect on public attitudes toward drones [9], that study was conducted in Australia and it is unclear whether the findings will generalize to the U.S. On the other hand, we might expect terminology to have no effect in the U.S. because the term "drones" has been commonly used by the media and others when referring to commercial applications of the technologies, thereby potentially reducing the association between the term "drone" and military activity.

Even if terminology does not affect public perceptions, other communicative factors may. A particularly common finding in the social sciences is that humans tend to be more strongly motivated to avoid losses or prevent harm than to approach gains or promote benefits [10], [11]. For example, very different levels of support are offered when inquiring about "saving lives" (a benefit) versus "preventing deaths" (a harm)-with people generally more supportive of efforts to prevent deaths than to save lives [10]. If this framing effect applies to the current context, framing of UAVs in terms of harms they can prevent should result in more support than framing them in terms of benefits they might promote. Some research, however, suggests that opinions are less susceptible to framing effects when people have thought more deeply and analytically about the issues [12], [13]. Thus, if framing effects are not found, or are found but appear to be decreasing over time, this could indicate that the public is forming more robust opinions that are less influenced by communication factors. In lieu of any prior evidence or significant event occurring between surveys, we had no reason to expect that the framing effects would not occur or would change over time. Thus, our first research question (RQ) and hypothesis $(\mathrm{H})$ is as follows:

○ RQ1: Is public support impacted by communicative factors such as terminology describing the technology and/or promotion and prevention framing, and do these impacts change over time?

○ H1: Consistent with prior research, terminology will have no impact on public support, but framing will have a significant impact favoring prevention framing that is consistent over time. 


\section{UAV Autonomy}

We also examined the effect of UAV autonomy on U.S. public support. The effect of the autonomy of UAVs on public support has been studied in the context of military drones, where the primary ethical concerns are related to risk of collateral damage and the use of conscience-free weapons making life-and-death decisions [14], [15]. The autonomy of other technologies has also raised public concern - for example, the public has been leery of self-driving cars [16]. UAV autonomy has been less studied in the context of civilian uses. We sought to fill that gap by examining autonomy as it relates to different UAV purposes. We hypothesized that autonomy will matter less in domains where automation increases efficiency and reliability without raising clear ethical concerns. For example, many have suggested that economic topics like budgeting and taxes are less relevant to people's moral and ethical concerns than life and death topics like abortion and the death penalty (see review in [17]). Wariness of self-driving cars could also be related to fears about deaths and injuries. In the context of security and defense, respondents might imagine the UAVs autonomously doing harm. However, UAV autonomy may be less related to public support when UAVs are used for economic or environmental goals. Thus, our second research question and hypothesis is:

○ RQ2: Does autonomy of the UAVs affect public support (and/or does it depend on the purpose of the UAVs)?

$\circ \mathrm{H} 2$ : Autonomy will have a negative influence on support in the context of using UAVs for security, but will have less or no influence in the context of using UAVs for economic or environmental purposes.

\section{UAV Purpose, Perceptions of the UAV End-User, and Political Polarization}

Prior studies suggest UAV purposes influence attitudes towards UAVs, in both the U.S. and elsewhere [18]. U.S. public opinion is rather positive in the context of military [19], [20] and security [21], [22]. Further, polls suggest the U.S. public supports UAV use for search and rescue and scientific research purposes, while being less favorable toward every day commercial uses such as package 
delivery or local law enforcement (e.g., crowd monitoring and crime detection) [23].

However, the extent to which public attitudes toward UAVs are or may be becoming politically polarized has been given only scant attention to date [23]. Such investigations are important given the manner in which public polarization has impacted progress related to other science and technologies. For example, public responses to genetically modified foods was quite different in the Europe versus the U.S. [24].

We explored the possible provocation of political polarization around UAVs in two ways: First, we explicitly tied certain UAV capabilities to commonly studied political issues (e.g., water sampling in the service of environmental conservation, or using commercial UAVs to build a strong economy). Second, we varied the actor using the UAV (i.e., public or private domain). There are political differences in attitudes toward business versus governmental actors in different situations. For example, self-identified conservatives generally favor free market forces over governmental involvement, and [25] found that conservatives report less trust in government than liberals. Yet greater trust in government has been found among conservatives when considering foreign rather than domestic policy [26], and conservatives may support government involvement when it comes to security and defense [27]. These results suggest that UAV purpose and end user need to be considered in combination.

Related to the experimental variation of UAV purposes and end users, we also assessed issue attitudes (toward environmental, security and economic issues) and perceptions of end-user trustworthiness. Miethe et al. [23] suggest that, among other factors, distrust of actors using the UAVs may have resulted in low support for use of UAVs for crowd monitoring or use near one's home. Including measures of issue attitudes and actor trustworthiness allowed us to test whether any differences related to actor, or actor and purpose were due to differences in such attitudes. Our final research questions and hypotheses were as follows:

- RQ3: What are the most important factors affecting public support for UAV development and use (and did these factors change from 2014 to 2015)?

$\circ \mathrm{H} 3$ : Consistent with prior research, the purpose of UAVs will be among the most important predictors across both 2014 and 2015 . 
O RQ4: What conditions, if any, appear to elicit politically polarized responses (and did these conditions change from 2014 to 2015)?

○ H4: Polarized support will be dependent upon both the purpose of UAVs and the actor using them, with heightened polarization apparent when UAVs are used to address polarizing issues (e.g., the environment) and used by end users that are differentially trusted dependent upon ideology (e.g., the government).

\section{Methodology}

\section{Study Design}

To investigate our research questions, we used a "vignette survey experiment" [28] administered to a convenience (i.e., not representative) sample comprised of U.S. Amazon MTurk workers. After asking whether participants had heard of the technology, the survey presented each participant with a brief definition of the technology and then provided a short scenario depicting an agency investigating possible future uses of UAVs. Features of the scenario were manipulated in a fully-crossed design. Table 1's first row depicts the template used to develop the scenarios. Instances of each item (italicized within brackets) were selected dependent upon randomly assigned condition from the corresponding categories in the Table.

\section{Measures}

Immediately following the experimentally manipulated scenario, we assessed our primary dependent measure, support for the UAVs, and measured perceptions of the trustworthiness, competence, and distrustworthiness of the end user. Our three trust-relevant variables (hereafter referred to collectively as measures of trustworthiness) were determined based on theory and preliminary factor analyses [29]. As shown in Table 2, we averaged across multiple items to create internally reliable scales with Cronbach alpha values greater than or equal to 0.7 , as is commonly recommended. 
Table 1. Manipulations of conditions within the vignette survey experiment.

Imagine that... For the next questions, imagine that [Public/private] has established [Agencies] that is investigating the use of [Technology] to [Purpose 1]. For example, the [Public/private] might [Purpose2]. The [Technology] they are using are [Autonomy].

\begin{tabular}{|c|c|c|c|c|}
\hline Public/Private & \multirow{2}{*}{\multicolumn{2}{|c|}{$\begin{array}{l}\text { The U.S. government } \\
\text { Public/Government }\end{array}$}} & \multicolumn{2}{|l|}{ A private U.S. company } \\
\hline Agencies & & Public/Government & \multicolumn{2}{|l|}{ Private/Business } \\
\hline Economic & \multirow{3}{*}{\multicolumn{2}{|c|}{$\begin{array}{l}\text { A new Institute of Economic Development } \\
\text { A new Institute of Environmental Enhancement } \\
\text { A new Institute of Public Safety and Security }\end{array}$}} & \multirow{2}{*}{\multicolumn{2}{|c|}{$\begin{array}{l}\text { An Economic Development Research Unit } \\
\text { An Environmental Enhancement Research Unit }\end{array}$}} \\
\hline Environment & & & & ncement Research Unit \\
\hline Security & & & \multicolumn{2}{|c|}{ A Public Safety and Security Research Unit } \\
\hline Technology & \multicolumn{2}{|c|}{ Drone(s) $\quad$ Aerial robot(s) } & $\begin{array}{l}\text { Unmanned aerial } \\
\text { vehicle }(\mathrm{s})-\mathrm{UAV}(\mathrm{s})\end{array}$ & $\begin{array}{l}\text { Unmanned aerial } \\
\text { system(s) - UAS(s) }\end{array}$ \\
\hline Purposes & \multicolumn{2}{|l|}{ Promotion Focus } & \multicolumn{2}{|l|}{ Prevention Focus } \\
\hline Economic & \multicolumn{2}{|c|}{$\begin{array}{l}\text { 1) [Technology] used to promote economic } \\
\text { growth } \\
\text { 2) [for example] to be used to make tasks } \\
\text { such as package delivery more efficient, } \\
\text { possibly allowing business owners to } \\
\text { expand their businesses and profits and } \\
\text { become more competitive, thereby } \\
\text { improving the U.S. economy. }\end{array}$} & \multicolumn{2}{|c|}{$\begin{array}{l}\text { 1) [Technology] used to prevent economic } \\
\text { decline } \\
\text { 2) [for example] to be used to make tasks such } \\
\text { as package delivery more efficient, possibly } \\
\text { allowing business owners to cut losses and } \\
\text { costs and avoid business closures, thereby } \\
\text { helping the U.S. economy to remain stable. }\end{array}$} \\
\hline Environment & \multicolumn{2}{|c|}{$\begin{array}{l}\text { 1) [Technology] used to discover or create } \\
\text { additional natural resources in our country } \\
\text { 2) [for example] to be used to gather water } \\
\text { samples in order to discover and document } \\
\text { clean water sources, or other sources of } \\
\text { valuable natural resources. }\end{array}$} & \multicolumn{2}{|c|}{$\begin{array}{l}\text { 1) [Technology] used to monitor and } \\
\text { protect natural resources in our country } \\
\text { 2) [for example] be used to gather water samples } \\
\text { in order to detect water quality problems, } \\
\text { or other threats to valuable natural resources. }\end{array}$} \\
\hline Security & \multicolumn{2}{|c|}{$\begin{array}{l}\text { 1) [Technology] used to promote public } \\
\text { confidence in everyday security } \\
\text { 2) [for example] to be used to actively seek out } \\
\text { illegal activities, potentially allowing for the } \\
\text { prosecution and punishment of a greater } \\
\text { number of crimes happening on U.S. soil, } \\
\text { resulting in increases in public safety. }\end{array}$} & \multicolumn{2}{|c|}{$\begin{array}{l}\text { 1) [Technology] used to prevent public } \\
\text { concerns about everyday security } \\
\text { 2) [for example] to help monitor and prevent } \\
\text { harm from illegal activities, potentially } \\
\text { allowing the prevention of increases } \\
\text { in crimes happening on U.S. soil. }\end{array}$} \\
\hline Autonomy & $\begin{array}{l}\text { Fully autonomous - } \\
\text { meaning that they are entirely } \\
\text { controlled by computers that have } \\
\text { been programmed to guide their } \\
\text { actions. Human manual control is } \\
\text { not used. }\end{array}$ & $\begin{array}{l}\text { Partially a } \\
\text { meaning } t \\
\text { both by cc } \\
\text { programm } \\
\text { and manu } \\
\text { to control }\end{array}$ & $\begin{array}{l}\text { utonomous - } \\
\text { hat they are controlled } \\
\text { mputers that have been } \\
\text { ed to guide their actions } \\
\text { ally by humans trained } \\
\text { them remotely. }\end{array}$ & $\begin{array}{l}\text { Not autonomous - } \\
\text { meaning that they are entirely } \\
\text { manually controlled by people } \\
\text { with remote controls that have } \\
\text { been trained to guide the } \\
\text { [Technology]'s actions. } \\
\text { Computer automated controls } \\
\text { are not used. }\end{array}$ \\
\hline
\end{tabular}


Table 2. Measures of support for UAVs and end-user trustworthiness.

\begin{tabular}{|c|c|c|c|}
\hline Subscale & Item & Response Scale & $\begin{array}{l}\text { Cronbach's alpha } \\
\text { (internal consistency) }\end{array}$ \\
\hline Support for UAV Use & $\begin{array}{l}\text { To what extent do you approve of [Actor] } \\
\text { using [Technology] for the purposes described } \\
\text { above? } \\
\text { To what extent would you support or resist [Actor] } \\
\text { use of [Technology] for the purposes described above? } \\
\text { For example, how willing would you be to vote to } \\
\text { allow such uses or have public funds promote such uses? }\end{array}$ & $\begin{array}{l}\text { Strongly Resist (1) to } \\
\text { Strongly Support (7) }\end{array}$ & 0.93 \\
\hline \multicolumn{4}{|c|}{ Below, indicate your opinions about how [Actor] would behave when using [Technology] for the purposes described above. } \\
\hline Trustworthiness & $\begin{array}{l}\text { Only use the [Technology] to benefit the public at large } \\
\text { Be honest with the public about anything they find or } \\
\text { do using the [Technology] } \\
\text { Be transparent (open) about how, when, and why } \\
\text { they are using the [Technology] } \\
\text { Use the [Technology] to achieve values important to you }\end{array}$ & Never (1) to Always (6) & 0.87 \\
\hline Distrustworthiness & $\begin{array}{l}\text { Use the [Technology] for their own selfish benefit } \\
\text { Be dishonest about anything they find or do } \\
\text { using the [Technology] } \\
\text { Hide information about how, when and why they } \\
\text { are using the [Technology] } \\
\text { Use [Technology] to support values that you } \\
\text { disagree with }\end{array}$ & Never (1) to Always (6) & 0.85 \\
\hline Competence & $\begin{array}{l}\text { Be competent in their use of [Technology] } \\
\text { Be incompetent in their use of [Technology] (reversed) }\end{array}$ & Never (1) to Always (6) 0.70 & \\
\hline
\end{tabular}

Near the end of the survey we assessed demographics such as age, gender, and ethnicity. We also assessed scenario-specific issue attitude (e.g., I believe [the protection of our environmental resources; U.S. national security; a strong U.S. economy] should be the nation's top priority) with response options ranging from strongly disagree (1) to strongly agree (7). Political ideological identity was assessed as the average across three items asking participants to rate the extent to which they were strongly liberal (1) to strongly conservative (7) on economic issues, social issues, and overall (Cronbach's alpha $=0.91$ ).

\section{Participants}

A total of 576 participants were recruited in late 2014 and 301 in late 2015 via MTurk. All participants were American citizens and were paid 25 cents ( 0.25 USD) in 2014 or 50 cents (0.5 USD) in 2015. As is common with MTurk, both samples, on average, self-reported they 
were somewhat more liberal than conservative (see Figure 2). In 2014, there were slightly more men than women (299 versus 277) and slightly more women than men in 2015 (167 versus 134). The samples were of a similar age distribution with 2014 having a mean age of 36.2 years (SD: 12.8 ) and 2015 having a mean age of 36.6 years (SD: 12.3 ).

\section{Results}

The data were analyzed using the Statistical Program for Social Sciences (IBM SPSS Statistics 23). To answer our research questions and test our hypotheses, we conducted correlation and multiple regression analyses.

Correlation analyses allow us to examine the strength of the relationship between any two variables. As shown in Table 3, among the experimentally varied factors, the highest correlations and thus the strongest relationships with support involved UAV purpose. The negative correlation between support and security purposes, and positive correlation between support and environmental uses, indicates support was lowest for security purposes and highest for environmental purposes.

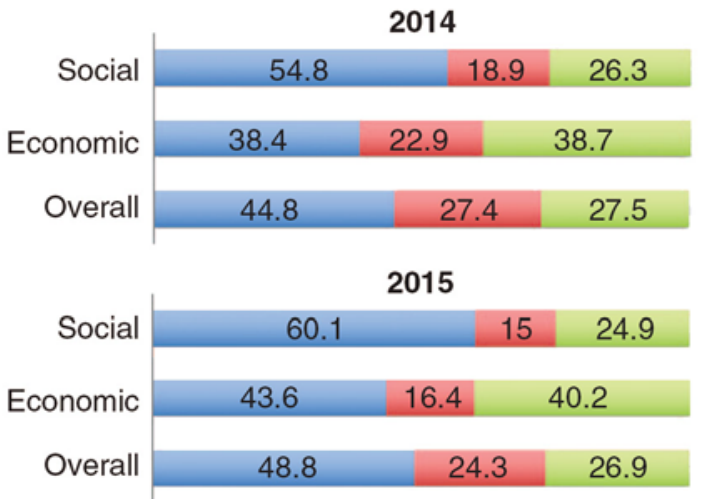

Liberal (1-3) $\quad$ Centrist (4) $\quad$ Conservative (5-7)

Figure 2. Illustration of distribution of sample responses (numbers indicate percent of sample) to survey questions concerning self-reported ideology. 
Table 3. Pearson correlations between UAV support and each of our manipulated and measured variables.

\begin{tabular}{|c|c|c|c|c|}
\hline & 2014 & 2015 & Both Years & \%Var \\
\hline \multicolumn{5}{|l|}{ Manipulated Variables } \\
\hline \multicolumn{5}{|l|}{ Purposes } \\
\hline Security use & $-0.30^{* * *}$ & $-0.27^{\star * *}$ & $-0.29 * \star \star$ & $8.41 \%$ \\
\hline Environmental use & $0.24^{\star \star *}$ & $0.31^{\text {***}}$ & $0.27^{\star \star \star}$ & $7.29 \%$ \\
\hline Economic use & 0.06 & -0.04 & 0.03 & $0.09 \%$ \\
\hline \multicolumn{5}{|l|}{ End-User } \\
\hline Business (vs. Governmen & nt) $-0.11^{\star *}$ & -0.03 & $-0.08^{*}$ & $0.64 \%$ \\
\hline \multicolumn{5}{|c|}{ Autonomy } \\
\hline Autonomous & -0.03 & 0.09 & 0.01 & $0.01 \%$ \\
\hline Manual & -0.04 & -0.07 & -0.05 & $0.25 \%$ \\
\hline Partially Autonomous & 0.07 & -0.02 & 0.04 & $0.16 \%$ \\
\hline \multicolumn{5}{|l|}{ Terminology } \\
\hline UAS term & -0.03 & -0.09 & -0.05 & $0.25 \%$ \\
\hline UAV term & 0.00 & 0.02 & 0.01 & $0.01 \%$ \\
\hline Aerial robot term & 0.05 & 0.01 & 0.03 & $0.09 \%$ \\
\hline Drone term & -0.02 & 0.06 & 0.01 & $0.01 \%$ \\
\hline \multicolumn{5}{|l|}{ Framing } \\
\hline Promotion (vs. preventio & on) $-0.12^{\star *}$ & -0.03 & $-0.09^{*}$ & $0.81 \%$ \\
\hline \multicolumn{5}{|l|}{ Measured Variables } \\
\hline Female & -0.03 & -0.02 & -0.02 & $0.04 \%$ \\
\hline Age & -0.01 & -0.08 & -0.03 & $0.09 \%$ \\
\hline Ideology (Conservativism & m) -0.05 & 0.07 & -0.01 & $0.01 \%$ \\
\hline Issue attitude & $0.17^{* * *}$ & $0.24^{* * *}$ & $0.20^{* * *}$ & $4.00 \%$ \\
\hline \multicolumn{5}{|l|}{ Perceptions of end-users } \\
\hline Trustworthiness & $0.50^{\star \star \star}$ & $0.55^{\star \star *}$ & $0.52^{* * *}$ & $27.04 \%$ \\
\hline Dis-trustworthiness & $-0.42^{* \star *}$ & $-0.48^{\star \star *}$ & $-0.44^{\star \star *}$ & $19.36 \%$ \\
\hline Competence & $0.39^{\star * *}$ & $0.47^{\star * *}$ & $0.42^{* * *}$ & $17.64 \%$ \\
\hline
\end{tabular}

Notes: $2014 N=576,2015 N=301 .+p<0.10,{ }^{*} p<0.05,{ }^{* *} p<0.01,{ }^{* * *} p<0.001 . \%$ Var is the square of the Pearson correlation across both years and estimates the variance shared by the predictor and UAV support.

Figure 3 illustrates the distribution of responses to questions assessing public support or resistance by UAV purpose and year. There was a relatively bi-modal distribution of support ratings for security purposes in both 2014 and 2015, indicating public polarization. Ratings of support for economic purposes were negatively skewed, resulting in more support on average than for security purposes. However, there appeared to be increasing polarization of responses in 2015 relative to 2014. That is, the percentage of those strongly resisting use of UAVs for economic purposes was greater than those expressing more moderate resistance in 2015. Finally, support ratings for use of UAVs 

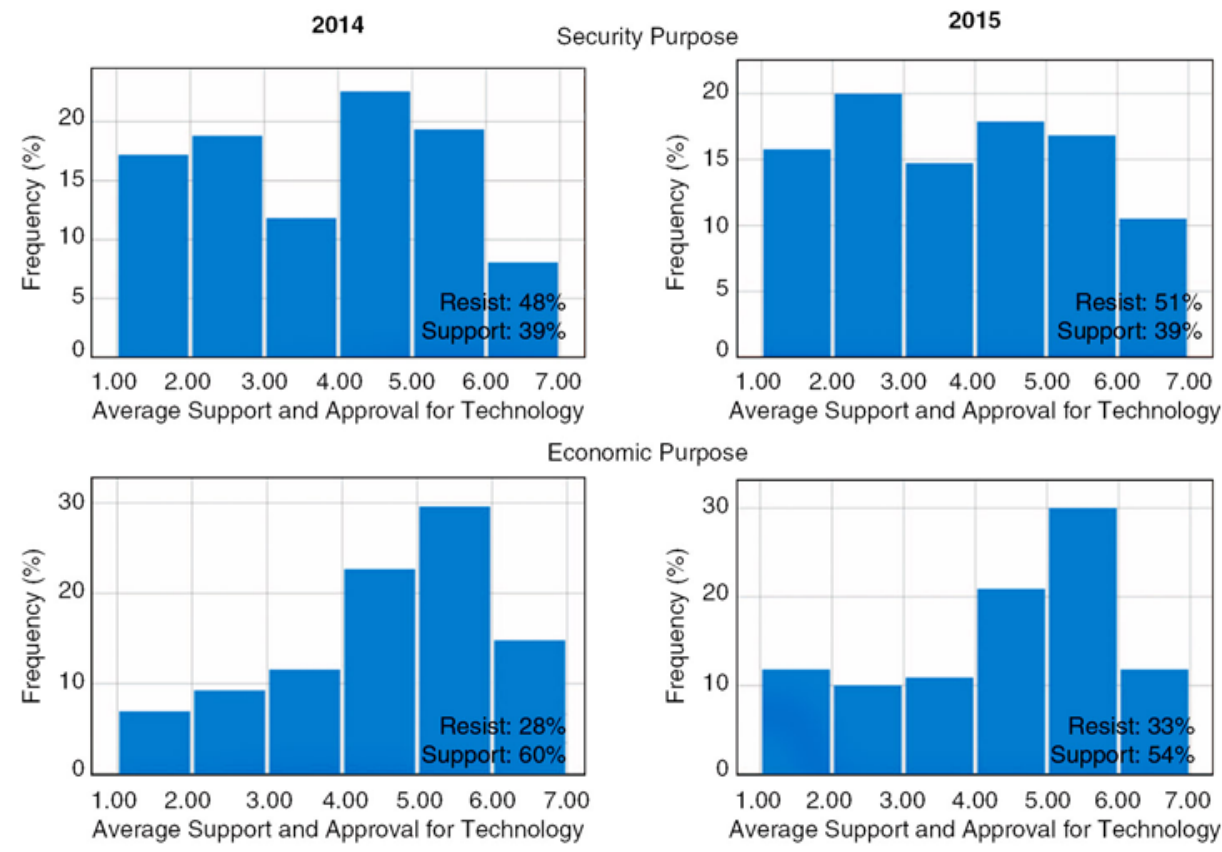

Environmental Purpose
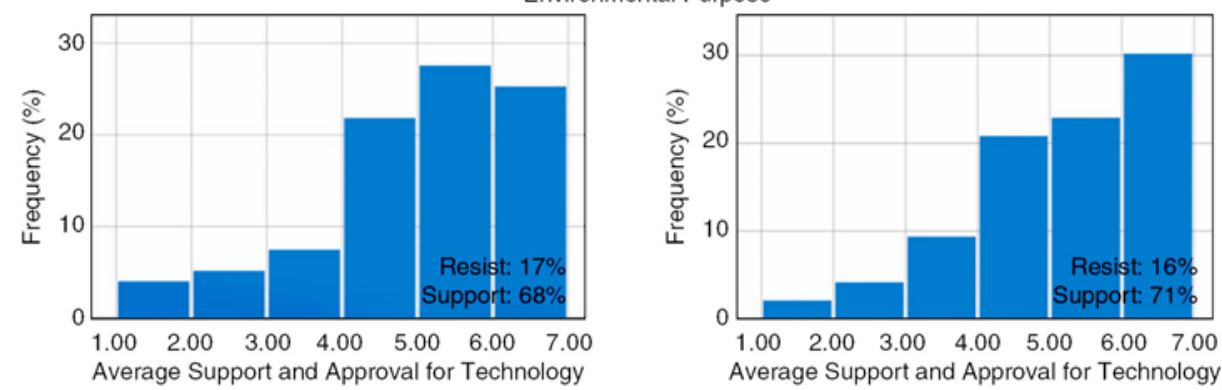

Figure 3. Distribution of rated support or resistance for the development and use of UAVs by purpose and year. Note: Support was assessed by averaging two items (see Table 2) resulting in a mean between 1 and 7. Percentages of resistors and supporters sum to less than 100 because a small percentage of persons' mean scores were at exactly "4" (neutral) and thus were not counted as resistors or supporters.

for environmental purposes were negatively skewed in 2014, and even more negatively skewed in 2015, resulting in the highest average levels of support for environmental purposes.

Among the other variables listed in Table 3, there were weaker but significant relationships with UAV support favoring prevention-focused framing and end use by the government over private business. Among the non-experimentally varied variables, as expected, there were relatively strong effects of end-user trustworthiness and of issue attitudes relevant to the scenario assigned to the participant. 
Multiple regression procedures provide a different measure of the importance of variables for predicting public support by identifying variables that account for independent variance above and beyond other variables. We first tested whether the effects of each of our variables depended on time (this is done by testing for statistical interactions with time). These analyses indicated that the overall main effects did not change between 2014 and 2015. We therefore ignore the effect of time in most of our remaining analyses. Next, we examined a regression model in which the experimentally varied factors were entered on Step 1 and the measured variables were entered on Step 2. This allows us to see how important each variable is when it is competing with different combinations of other variables. Note that we standardized the measured predictor variables so that they would have a mean of zero (representing the average response) and a standard deviation of 1 , in order to make results easier to interpret. Table 4 shows the Step 1 and 2 models' effects, which we next discuss in relation to our research questions and hypotheses.

\section{Response to RQ1: U.S. Public Support is Impacted (Slightly) by Framing but not by Terminology}

Table 4 provides evidence supporting our hypothesis (H1) that terminology will have no impact on public support in the U.S., but framing will have a significant impact favoring prevention framing. Consistent with prior research in social psychology, prevention framing in terms of protecting people from harm was associated with slightly more support (predicting a 0.23 point increase in support on the 7-point scale) compared to promotion framing. However, the overall variance accounted for by prevention or promotion framing (beyond that accounted for by other variables) was small (independently only accounting for less than one-half percent of the total variance in support for UAVs).

Note that, although terminology did not impact support for the technology, it did impact familiarity. A total of $92 \%$ of respondents across both years indicated "yes" they had heard of drones. Only 59\% indicated they had heard of UAVs, 37\% had heard of UASs, and 33\% had heard of aerial robots. These results were similar across both years of the survey. 
Table 4. Results of hierarchical regression analyses predicting support with experimentally varied and measured variables.

\begin{tabular}{|c|c|c|c|c|c|c|}
\hline & \multicolumn{3}{|c|}{ Step 1} & \multicolumn{3}{|c|}{ Step 2} \\
\hline & B & SE & $\begin{array}{c}\text { Indep. } \\
\text { Variance }\end{array}$ & B & SE & $\begin{array}{c}\text { Indep. } \\
\text { Variance }\end{array}$ \\
\hline \multicolumn{7}{|l|}{$\overline{\text { Step } 1}$} \\
\hline (Constant) & $5.26^{\star * \star}$ & 0.165 & & $5.15^{\star \star \star}$ & 0.138 & \\
\hline Security use (vs. envir.) & $-1.36^{\star \star \star}$ & 0.133 & $10.52 \%$ & $-1.15^{\star \star \star}$ & 0.112 & $7.46 \%$ \\
\hline Economic use (vs. envir.) & $-0.58^{\star \star \star}$ & 0.129 & $2.08 \%$ & $-0.58^{\star \star \star}$ & 0.108 & $2.05 \%$ \\
\hline Business (vs. Government) & $-0.26^{*}$ & 0.106 & $0.59 \%$ & $-0.30^{\star \star}$ & 0.088 & $0.80 \%$ \\
\hline Autonomous (vs. partially) & -0.04 & 0.129 & $0.01 \%$ & 0.02 & 0.108 & $0.00 \%$ \\
\hline Manual (vs. partially) & $-0.22+$ & 0.129 & $0.29 \%$ & -0.08 & 0.108 & $0.04 \%$ \\
\hline UAS term (vs. drone) & -0.18 & 0.149 & $0.15 \%$ & -0.09 & 0.124 & $0.04 \%$ \\
\hline UAV term (vs. drone) & 0.04 & 0.149 & $0.01 \%$ & -0.04 & 0.124 & $0.01 \%$ \\
\hline Aerial robot (vs. drone) & 0.09 & 0.147 & $0.04 \%$ & 0.12 & 0.123 & $0.06 \%$ \\
\hline Promotion (vs. prevention) & $-0.23^{*}$ & 0.106 & $0.48 \%$ & $-0.24^{\star *}$ & 0.088 & $0.52 \%$ \\
\hline \multicolumn{7}{|l|}{ Step $2^{a}$} \\
\hline Trustworthiness & & & & $0.52^{* * *}$ & 0.063 & $4.69 \%$ \\
\hline Distrustworthiness & & & & $-0.16^{*}$ & 0.064 & $0.45 \%$ \\
\hline Competence & & & & $0.27^{\star \star \star}$ & 0.059 & $1.53 \%$ \\
\hline Issue attitude & & & & $0.12^{*}$ & 0.046 & $0.46 \%$ \\
\hline Ideology & & & & -0.01 & 0.044 & $0.00 \%$ \\
\hline $\mathrm{F}$ & \multicolumn{3}{|c|}{$(9867)=13.79, p<0.001$} & \multicolumn{3}{|c|}{$(14862)=40.12, p<0.001$} \\
\hline$R^{2}$ & \multicolumn{3}{|c|}{0.13} & \multicolumn{3}{|c|}{0.40} \\
\hline
\end{tabular}

Step 2

$+p<0.10,{ }^{*} p<0.05,{ }^{* *} p<0.01,{ }^{* * *} p<0.001$. B indicates the expected change in support relating to a 1-unit change in the predictor variable. Indep. Variance indicates the non-overlapping variance accounted for by the predictor above and beyond the variance accounted for by the other variables.

a. Step 2 variables were transformed to $z$-scores such that 0 equals the mean response and the $B$ value refers to the change in support for a 1 standard deviation increase in the predictor.

\section{Response to RQ2: UAV Autonomy did not Impact UAV Support, Regardless of Purpose}

Table 4 results indicate that, as a main effect, autonomy of the UAVs does not appear to affect public support, although there was slightly less support for fully manual UAVs than partially autonomous UAVs in Step 1 of the model. To examine whether the effect of autonomy depends on the purpose of the UAVs, we conducted another regression analysis (not shown in Table 4) that tested for the interaction between the purpose and autonomy variables. The interaction was not statistically significant, which indicates that our hypothesis ( $\mathrm{H} 2)$ that 
autonomy will have different effects on support depending on purpose, was not supported. Autonomy did not affect our respondents' reported levels of support for UAVs, regardless of the purpose of the UAVs.

\section{Response to RQ3: Purpose and End-User Trustworthiness are the Most Important Predictors of Support}

The results presented in Table 4 further confirm the importance of UAV purpose for impacting support, as purpose accounts for about $13 \%(11+2 \%)$ of the independent variance in the Step 1 model, while end user and framing each independently account for vastly less only about one-half of one percent of the variance. Even when perceptions of actor trustworthiness, issue attitude, and ideology are included in the model in Step 2, UAV purposes continue to predict the most variance in public support, followed by perceptions of end-user trustworthiness.

Taken together, our results support $\mathrm{H}_{3}$ that UAV purpose is among the most important predictors of UAV support. The B statistics in Table 4 indicate, for example, controlling for all other variables (Step 2), use of UAVs for security purposes reduces support by 1.15 points on the 7-point scale, compared to environmental purposes. Using UAVs for economic (rather than environmental) purposes reduces support by 0.58 points. Additionally, our analyses find that our sample supported use by government more than by businesses (Table 4). Further, issue attitude, trustworthiness perceptions, and ideology do not completely explain the effects of purpose and end user. We know this because purpose and end user remain significant predictors of support even when those other variables are included in the model.

\section{Response to RQ4: Political Polarization can be Evoked, but is Small and the Pattern Changes over Time}

To examine whether certain conditions appeared to elicit politically polarized responses, and whether those conditions changed from 2014 to 2015, we tested for differences in the effect of ideology dependent on UAV purpose, actor, and year. Specifically, we examined the four-way interaction in a multiple regression while including all subsumed interactions and main effects also in the model. Due to space constraints, the full model results are not presented but are available 
Table 5. Effects of self-reported ideology on support under different experimentally varied conditions as estimated by subsample correlations and regression coefficients computed under different conditions.

\begin{tabular}{|c|c|c|c|c|c|c|c|c|}
\hline & \multicolumn{4}{|c|}{2014} & \multicolumn{4}{|c|}{2015} \\
\hline & Corr & $\%$ Var & B & $\%$ Var & Corr & $\%$ Var & B & $\%$ Var \\
\hline \multicolumn{9}{|c|}{ Government use for... } \\
\hline Economic & -0.09 & $0.86 \%$ & -0.14 & $0.08 \%$ & 0.12 & $1.44 \%$ & 0.18 & $0.08 \%$ \\
\hline Security & -0.02 & $0.05 \%$ & -0.04 & $0.00 \%$ & $0.29 *$ & $8.18 \%$ & $0.48^{*}$ & $0.55 \%$ \\
\hline Environment & $-0.27^{\star \star}$ & $7.02 \%$ & $-0.35^{\star}$ & $0.48 \%$ & $-0.32^{*}$ & $10.43 \%$ & -0.35 & $0.26 \%$ \\
\hline \multicolumn{9}{|c|}{ Business use for... } \\
\hline Economic & -0.09 & $0.77 \%$ & -0.14 & $0.08 \%$ & 0.15 & $2.37 \%$ & 0.25 & $0.16 \%$ \\
\hline Security & $0.24^{*}$ & $5.71 \%$ & $0.40^{*}$ & $0.64 \%$ & -0.00 & $0.00 \%$ & -0.00 & $0.00 \%$ \\
\hline Environment & -0.18 & $3.28 \%$ & -0.29 & $0.25 \%$ & 0.11 & $1.25 \%$ & 0.15 & $0.05 \%$ \\
\hline
\end{tabular}

$+p<0.10,{ }^{*} p<0.05,{ }^{* *} p<0.01,{ }^{* * *} p<0.001$. These follow-ups were justified by a significant four-way interaction $\left(R^{2}\right.$-change $=0.006, F$-change $\left.(2,853)=3.09, p=0.046\right)$ indicating that the strength of the ideology-support relationship varied by end-user, purpose, and year of the survey. Corr=Pearson correlation. \%var for corr indicates the total variance shared by self-reported ideology and support. \%Var for B indicates the independent variance accounted for based on regression results.

from the first author. However, the four-way interaction was statistically significant. This indicates that political polarization of support (i.e., the relationship between ideology and support) changed dependent upon UAV purpose, end user, and year.

To clarify how political polarization varied, Table 5 shows the strength of the ideology-support relationship under different conditions and Figure 4 illustrates the predicted mean support for UAVs dependent on the different factors. In Figure 4, the conditions under which significant ideology-support relationships were apparent are highlighted by the labeled bars. As shown in Table 5, our hypothesis (H4) was partially supported: polarization of support depended both on UAV purpose and end user. Specifically, ideology correlated with use of UAVs for environmental purposes by government in both 2014 and 2015 (Table 5 respective $r s=-0.27,-0.32$, ps $<0.05$ ), with the negative correlations indicating that conservatives were less supportive of UAVs than liberals under those conditions. In addition, Table 5 and Figure 4 show that use of UAVs for security resulted in polarization such that conservatives were more supportive of that use in both 2014 and 2015 - but the polarization was associated with different end users in 2014 (business) and 2015 (government). 
2014

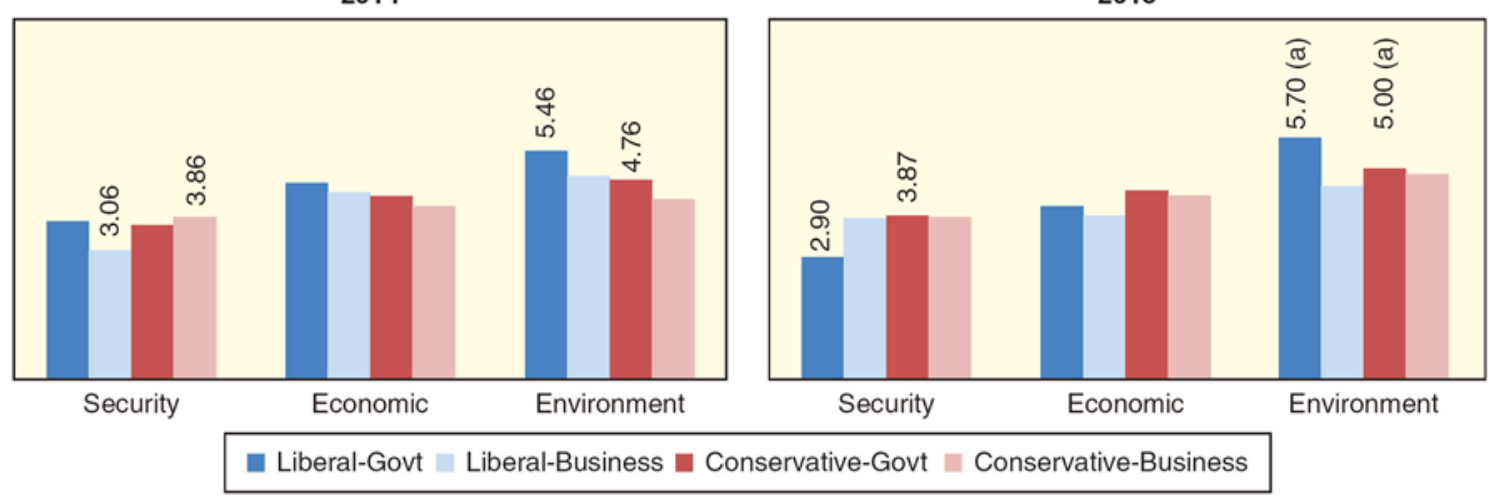

Figure 4. Predicted UAV support by year, UAV purpose, UAV end-user, and ideology (computed at -1 and +1 standard deviation from the sample mean ideology). Notes: Bars representing the conditions under which there occurred significant relationships between ideology and support are labeled. (a) Ideology-support correlation but not the ideology regression coefficient was significant in 2015 .

Finally, although the results are partially supportive of our hypothesis, we note that the effect of ideology (and thus political polarization) is generally small, only accounting for a fraction of a percent of the variance in public support for UAVs. This amount is not always statistically significant (see Table 5). In addition, the four-way and all three-way interactions became non-significant when issue attitudes and trustworthiness variables were included in the model. This suggests that changes in polarization over time are due to the differences in issue attitudes and trustworthiness ratings between our 2014 and 2015 samples.

\section{Discussion and Recommendations}

As stated by [30], "it is important to note that on one hand a new technology may bring about radical changes in society, while on the other hand the fate of that technology rests with the society in which it is being applied" [30, p. 783]. The present work investigating U.S. public responses to UAV technologies is important, as it confirms and extends prior findings, thereby advancing understanding of U.S. public resistance to and support of UAVs, while also suggesting recommendations for UAV developers, end users, and policy makers. 
For example, terminology had no effect on public support, consistent with previous findings [9]. This may suggest UAV developers, policy makers, and users should not waste energy fighting for specific terminology. Instead they should focus on the factors more important to the public, such as how, why, and by whom the UAVs will be used. It appears from these findings that members of the public translate between "drone" and other similar, but much less familiar, terms without a measureable change in attitude.

Second, the finding that prevention framing enhances support suggests that members of the public are more moved by appeals related to reducing threats than enhancing benefits. This strategy could emphasize how UAVs can be used to prevent or decrease risks rather than increasing convenience. For example, if designing UAVs for prescribed fires, more public support may be garnered by emphasizing how use of the UAVs protects workers and the public from dangerous situations, rather than emphasizing efficiency or even safety gains. However, the weakness of the effect suggests framing may not be a very powerful strategy for impacting public support.

Instead, focusing on valued purposes may be more powerful. Consistent with prior findings, support for UAVs varied significantly by purpose. In our samples, the greatest support was found for UAVs used for environmental purposes and the least support was found for use for security purposes. Because we used a convenience sample, this specific pattern may or may not generalize to the U.S. as a whole. Nonetheless, the results indicate that various U.S. publics are likely paying much more attention to UAV purpose - rather than to factors like terminology or framing-when deciding how much they support UAVs.

The public is also attending to who is using the UAVs and how much they trust them. Trustworthiness variables accounted for the second largest amount of variance after UAV purposes. Of the trustworthiness variables, positive trustworthiness perception was the strongest predictor of support, followed by perceived competence, and then perceived distrustworthiness (see Table 4 ). This indicates a relatively positive public context for UAVs (i.e., support is driven by reasons to trust users rather than by reasons to distrust) and could allow broader support for trusted entities, such as fire rescue personnel, to use UAVs. It also suggests that efforts to impact factors increasing perceived enduser trustworthiness, such as training and licensing, may result in 
greater support for their UAV uses. Regulatory or punitive responses aimed at reducing distrust in end users may be less effective.

It is worth highlighting that drone autonomy was mostly unrelated to public support in our two samples. Furthermore, the direction of one observed marginal effect indicated a preference for autonomy. This finding contrasts with the evidence of public concern when it comes to autonomous cars [31] or autonomous military drones [32] and suggests the public is not uniformly against all autonomous technologies. While further study is needed, it is possible that the public will even favor autonomous (or at least partially autonomous) over manually controlled UAVs under certain conditions.

Finally, political polarization was found to account for only a small amount of the variance in our data, even though we chose scenarios in which political polarization might be especially likely to occur. This is encouraging given the negative impact political polarization has sometimes had on the trajectories of other technologies, as previously noted. The polarization that we did find provided evidence that the purposes and actors supported by individuals were affected by attitudes such as ideology, and changed over time. Conservatives supported security purposes more than liberals under some conditions, and liberals supported environmental uses more than conservatives. Our analyses further indicate, to some extent, this polarization could be attributed to differences in trust in different end users and in issue attitudes.

Taken together, our results suggest the importance of being responsive to the values of specific target audiences while developing UAVs and while communicating to different publics about UAV development and usage. Such practices may reduce public resistance and, potentially, reactive legislation. One example of local ideologies impacting public acceptance and legislation is in the conservative, business-friendly state of Texas. There, a law was adopted to prevent the use of UAVs by the public for observing business practices after a meat processing plant was caught dumping blood into a river by a private environmental activist [33]. As another example, in California, use of drones over private property has been limited in response to privacy concerns over paparazzi flights near celebrity homes [34]. In both cases, locally important concerns have driven statewide legislation which may have unintended consequences on other UAV uses. By taking a proactive approach and responsively designing and 
communicating about UAVs in locally acceptable ways, researchers and industry may be able to gain support prior to being threatened with legislative action.

It is also important to consider public perceptions of end-user trustworthiness. Understanding which publics trust which end-users for different UAV uses is important, but may change over time and thus needs to be monitored and studied in greater detail. For example, there was a shift of politically polarized support for security purposes from the context of business users to government users from 2014 to 2015. End user also had an overall impact on public support. Our participants supported use by government over businesses, and this effect remained even when controlling for ideology and perceived trustworthiness of the end user (Table 4). This result, although deserving further investigation, is consistent with a recent survey of the Canadian public which found that more of their survey respondents supported rather than opposed use of UAVs for data collection by government groups but the opposite was true for use of UAVs by private industry [18].

\section{Limitations and Future Directions}

While there are limitations associated with the use of a convenience sample such as ours, other social science research comparing results from MTurk samples with national samples, especially related to effects of political ideology, suggest similar results are found in both types of samples [35]. Nonetheless, future work should involve representative national samples to increase generalizability to the U.S. as a whole.

We have focused on predictors of public support and resistance to UAV technologies. Given the importance of predictors such as purpose and end-user trustworthiness, future work should focus on gaining a better understanding of the causes of those factors. Also, it was a bit surprising that issue attitude did not reduce the impacts of UAV purpose when entered into the regression equation, and user trustworthiness perceptions did not reduce the effect of end user (Table 4). This suggests that issue attitudes are not the reason (or at least not the sole reason) for purpose effects, and trustworthiness perceptions were not the reason for end-user effects. Future research is needed 
to understand what other reasons may account for the differences.

Although UAV autonomy did not appear to affect public support for UAVs under the studied conditions, we anticipate that other information about UAV characteristics may be important and worthy of further study. People may be more sensitive to whether video is being recorded or streamed to another device, what information is being collected and how it will be stored, and whether they trust that the end user will limit its use and distribution. Indeed, in one notable case illustrating such concerns, a father shot a drone that he felt was spying on his daughter. A judge dismissed the charges against him. Subsequently, a bill was proposed to criminalize drone harassment in Kentucky [36].

Future research should also investigate additional factors that may impact UAV support. Our models only accounted for $40 \%$ of the total variance. Other factors that may be important include trust in the technology itself. Studies such as [37] that have indicated inappropriate comfort with UAVs at close distances $(<1.5 \mathrm{~m})$ for interaction, which could indicate over-trust in technologies under some conditions. Incorporating perceptions of specific risks and benefits of the technology, as well as specific characteristics of the platform, would likely increase variance accounted for and allow a broader understanding of public support across contexts.

\section{Author Information}

Lisa M. PytlikZillig is a research associate professor at the University of Nebraska Public Policy Center and University of Nebraska-Lincoln Social and Behavioral Sciences Research Consortium, Lincoln, NE, U.S.A. Email: lpytlikz@ nebraska.edu.

Brittany A. Duncan is an assistant professors in the Computer Science and Engineering Department at the University of Nebraska-Lincoln, Lincoln, NE, U.S.A. Email: bduncan@cse.unl.edu.

Sebastian Elbaum is the Bessey Professor in the Computer Science and Engineering Department at the University of Nebraska - Lincoln, Lincoln, NE, U.S.A. Email: elbaum@cse.unl.edu.

Carrick Detweiler is an associate professor in the Computer Science and Engineering Department at the University of Nebraska-Lincoln, Lincoln, NE, U.S.A. Email: carrick@cse.unl.edu. 


\section{References}

[1] D. Jenkins and B. Vasigh, "The Economic Impact of Unmanned Aircraft Systems Integration in the United States," Association for Unmanned Vehicle Systems International, Arlington, VA, 2013.

[2] J. Stilgoe, R. Owen, and P. Macnaghten, "Developing a framework for responsible innovation," Research Policy, vol. 42, pp. 1568-1580, 2013.

[3] D. M. Kahan, D. Braman, G. L. Cohen, J. Gastil, and P. Slovic, "Who fears the HPV vaccine, who doesn't, and why? An experimental study of the mechanisms of cultural cognition," Law and Human Behavior, vol. 34, pp. 501-516, 2010.

[4] D. M. Kahan, E. Peters, M. Wittlin, P. Slovic, L. L. Ouellette, D. Braman, et al., "The polarizing impact of science literacy and numeracy on perceived climate change risks," Nature Climate Change, vol. 2, pp. 732-735, 2012.

[5] B. Wolfgang, "Drone industry gives journalists not-so-subtle-hint- Don't use the word 'drones', The Washington Times, 2013.

[6] G.A. Gladney and T.L. Rittenburg, "Euphemistic text affects attitudes, behavior," Newspaper Research J., vol. 26, pp. 28-41, 2005.

[7] A. Bandura, C. Barbaranelli, G. V. Caprara, and C. Pastorelli, "Mechanisms of moral disengagement in the exercise of moral agency," J. Personality and Social Psychology, vol. 71, pp. 364-374, 1996.

[8] S.M. Mohammad and P.D. Turney, "Emotions evoked by common words and phrases: Using Mechanical Turk to create an emotion lexicon," in Proc. NAACL HLT 2010 Workshop on Computational Approaches to Analysis and Generation of Emotion in Text, 2010, pp. 26-34.

[9] R.A. Clothier, D.A. Greer, D.G. Greer, and A.M. Mehta, "Risk perception and the public acceptance of drones," Risk Analysis, vol. 35, pp. 1167-1183, 2015.

[10] A. Tversky and D. Kahneman, "The framing of decisions and the psychology of choice," Science, vol. 211, pp. 453-458, 1981.

[11] E.T. Higgins, "Promotion and prevention: Regulatory focus as a motivational principle," Advances in Experimental Social Psychology, vol. 30, pp. 1-46, 1998.

[12] E.R. Igou and H. Bless, "On undesirable consequences of thinking: Framing effects as a function of substantive processing," J. Behavioral Decision Making, vol. 20, pp. 125-142, 2007.

[13] A.F. Simon, N.S. Fagley, and J.G. Halleran, "Decision framing: Moderating effects of individual differences and cognitive processing," J. Behavioral Decision Making, vol. 17, pp. 77-93, 2004.

[14] M. C. Horowitz, "Public opinion and the politics of the killer robots debate," Research \& Politics, vol. 3, 2016.

[15] P. Lin, G. Bekey, and K. Abney, "Autonomous military robotics: Risk, ethics, and design," California Polytechnic State Univ., San Luis Obispo, CA, 2008.

[16] Morning Report, "National tracking poll \#170904: Crosstabulation results," Sept, 7-11, 2017, 2017.

[17] T.J. Ryan, "Reconsidering moral issues in politics," J. Politics, vol. 76, pp. 380397, 2014 . 
[18] S. Thompson and C. Bracken-Roche, "Understanding public opinion of UAVs in Canada: A 2014 analysis of survey data and its policy implications," $J$. Unmanned Vehicle Systems., vol. 3, pp. 156-175, 2015.

[19] S. Kreps, "Flying under the radar: A study of public attitudes towards unmanned aerial vehicles," Research \& Politics, vol. 1, pp. 1-7, 2014.

[20] J.I. Walsh, "Precision weapons, civilian casualties, and support for the use of force," Political Psychology, vol. 36, no. 5, pp. 507-523, 2015.

[21] J. Eyerman, C. Letterman, W. Pitts, J. Holloway, K. Hinkle, D. Schanzer et al., "Unmanned aircraft and the human element: Public perceptions and first responder concerns: Research brief," Institute for Homeland Security Solutions, Research Triangle Park, NC, 2013.

[22] M. Sakiyama, D.T. Miethe, D.J. Lieberman, J.M.S. Heen, and O. Tuttle, "Big hover or big brother? Public attitudes about drone usage in domestic policing activities," Security J., 2016.

[23] T.D. Miethe, J.D. Lieberman, M. Sakiyama, and E.I. Troshynski, "Public attitudes about aerial drone activities: Results of a national survey," Center for Crime and Justice Policy, Las Vegas, NV, 2014.

[24] G. Gaskell, M.W. Bauer, J. Durant, and N.C. Allum, "Worlds apart? The reception of genetically modified foods in Europe and the US," Science, vol. 285, pp. 384-387, 1999.

[25] T.E. Cook and P. Gronke, "The skeptical American: Revisiting the meanings of trust in government and confidence in institutions," J. Politics, vol. 67, pp. 784-803, 2005.

[26] M.J. Hetherington and T.J. Rudolph, "Priming, performance, and the dynamics of political trust," J. Politics, vol. 70, pp. 498-512, 2008.

[27] A. Malka and C.J. Soto, "Rigidity of the economic right? Menu-independent and menu-dependent influences of psychological dispositions on political attitudes," Current Directions in Psychological Science, vol. 24, pp. 137-142, 2015.

[28] C. Atzmüller and P.M. Steiner, "Experimental vignette studies in survey research," Methodology European J. Research Methods for the Behavioral and Social Sciences, vol. 6, pp. 128-138, 2010.

[29] L.M. PytlikZillig, J.A. Hamm, E. Shockley, M.N. Herian, T.M. Neal, C.D. Kimbrough et al., "The dimensionality of trust-relevant constructs in four institutional domains: Results from confirmatory factor analyses," J. Trust Research, 2016.

[30] N. Gupta, A.R. Fischer, and L.J. Frewer, "Socio-psychological determinants of public acceptance of technologies: A review," Public Understanding of Science, vol. 21, pp. 782-795, 2012.

[31] D. Howard and D. Dai, "Public perceptions of self-driving cars: The case of Berkeley, California," in Proc. Transportation Research Board 93rd Annual Meeting, 2013.

[32] C. Carpenter, "How do Americans feel about fully autonomous weapons?," DuckofMinerva.com, 2013.

[33] M. Schroyer, "Doing drone journalism in Texas? You could be fined $\$ 10,000$ or more," Professional Society of Drone Journalists, Sept. 15. 2015. 
[34] "Invasion of privacy," in An act to amend Section 1708.8 of the Civil Code, 2015-2016, ch. 521.

[35] S. Clifford, R.M. Jewell, and P.D. Waggoner, "Are samples drawn from Mechanical Turk valid for research on political ideology?," Research \& Politics, vol. 2, 2015.

[36] "Judge dismisses charges for man who shot down drone," WDRB Louisville News, Oct. 26, 2015.

[37] U. Acharya, A. Bevins, and B. Duncan, "Investigation of human-robot comfort with a small unmanned aerial vehicle compared to a ground robot," in Proc. IEEE/RSJ Int. Conf. Intelligent Robots and Systems (IROS), 2017. 